\title{
PEMETAAN NILAI SUSEPTIBILITAS MAGNETIK PASIR PANTAI GANDORIAH PARIAMAN SUMATERA BARAT
}

\author{
Putri Vanera Puspita*, Erwin \\ Jurusan Fisika Fakultas Matematika dan Ilmu Pengetahuan Alam Universitas Riau \\ *E-mail korespondensi: putrivanerapuspita@gmail.com
}

\begin{abstract}
Mapping of magnetic susceptibility values of sand of Gandoriah beach, Pariaman West Sumatera has been carried out. The composition of sand beach was identified using X-Ray Fluorescence Spectroscopy $(X R F)$ and the map of magnetic susceptibility and mass susceptibility of the sample were determined using Software Surfer 11. The samples were collected based on grid technique from 25 points location. The separation between magnetic particles and nan magnetic particles was done using iron sand separator for 1 time process.The result of the calculation of the magnetic degree of the sample using Iron Sand Separator for 1 time prosess showed that the values are in the range of 3,88\%-5,12\%. Magnetic and mass susceptibility values of the sample are in the range of $(603,3-1351,46) \times 10^{-5}$ and $(112,76-1086,85) \times 10^{-8} \mathrm{~m}^{3} / \mathrm{Kg}$ respectively. Magnetic and mass susceptibility of the concentrate (product of iron sand separator) are in the range of $(1367,55-2155,9) \times 10^{-5}$ and $(927,41-1774,28) \times 10^{-8} \mathrm{~m}^{3} / \mathrm{Kg}$ respectively. These values are in the range of Ilminate mineral that is $(220-380000) \times 10^{-5}$ and $(46-80000) \times 10^{-8} \mathrm{~m}^{3} / \mathrm{Kg}$ respectively. The percentage of $\mathrm{Fe}$ and Ti increases from 6,276 \% to $54,549 \%$ and from $0,441 \%$ to 5,102\% respectively after being processed by iron sand separator. The results also showed that magnetic susceptibility values increase toward the sea water.
\end{abstract}

Keywords: Gandoriah Pariaman Beach, Iron sand, Magnetic susceptibility, Mass susceptibility, Mapping.

\begin{abstract}
ABSTRAK
Pemetaan nilai suseptibilitas magnetik pasir pantai Gandoriah, Pariaman Sumatera Barat telah dilakukan. Komposisi pasir pantai di identifikasi menggunakan X-Ray Fluorescence Spectroscopy $(X R F)$. Peta susep tibilitas magnetik dan suseptibilitas massa sampel dibuat dengan menggunakan Software Surfer 11. Sampel dikumpulkan berdasarkan teknik grid dari 25 titik lokasi. Pemisahan antara partikel magnetik dan non magnetik dilakukan dengan menggunakan iron sand separator sebanyak 1 kali proses. Hasil perhitungan tingkat kemagnetan sampel menunjukkan bahwa nilainya berada dalam kisaran antara 3,88 \% - 5,12 \%. Nilai suseptibilitas magnetik dan massa sampel masing-masing berada dalam kisaran antara $(603,3-1351,46) \times 10^{-5}$ dan $(112,76-$ $1086,85) \times 10^{-8} \mathrm{~m}^{3} / \mathrm{Kg}$. Suseptibilitas magnetik dan massa konsentrat (hasil iron sand separator) masing-masing berada dalam kisaran antara $(1367,55-2155,9) \times 10^{-5}$ dan $(927,41-1774,28) \times 10^{-8}$ $\mathrm{m}^{3} / \mathrm{Kg}$. Nilai-nilai suseptibilitas magnetik dan massa yang ditemukan masing-masing berada dalam kisaran mineral Ilminate yaitu $(220-380000) \times 10^{-5}$ dan $(46-80000) \times 10^{-8} \mathrm{~m}^{3} / \mathrm{Kg}$. Persentase Fe dan Ti dalam pasir pantai meningkat berturut turut dari 6,276 \% menjadi 54,549\% dan $0,441 \%$ menjadi 5,102\% setelah diproses menggunakan iron sand separator. Hasil pemetaan nilai suseptibilitas magnetik menunjukkan bahwa nilai suseptibilitas magnetik lebih besar kearah air laut.
\end{abstract}

Kata kunci: Pantai Gandoriah Pariaman, Pasir pantai, Suseptibilitas magnetik, Susebtibilitas massa, Pemetaan

Diterima 21-11-2019 | Disetujui 15-01-2020| Dipublikasi 31-03-2020

\section{PENDAHULUAN}

Pasir pantai merupakan endapan pasir yang terdapat di sepanjang pantai seperti barat pulau Sumatera. Di pantai Sumatera Barat khususnya Pantai Gandoriah Pariaman ter dapat pasir 
pantai. Potensi dalam pengem bangan pertambangan pasir pantai disepanjang pantai Sumatera Barat umumnya memiliki kadar besi $2 \%$ sampai dengan $7 \%$ dan kete balannya bervariasi antara $2 \mathrm{~mm}$ sampai dengan $10 \mathrm{~cm}$ [1].

Pada saat ini, keberadaan pasir pantai ini belum dimanfaatkan secara maksimal. Oleh karena itu pula diadakan sintesis dari pasir besi sehingga diperoleh partikel magnetik dengan ukuran kecil (nanometer) yang memiliki nilai ekonomi tinggi. Fase magnetik pasir pantai yaitu fase magnetite $\left(\mathrm{Fe}_{3} \mathrm{O}_{4}\right)$ memiliki sifat magnetik yang lebih kuat. Dalam ukuran nanometer, maka fase magnetite ini bersifat super paramagnetik. Karena sifatnya yang dapat dikontrol oleh medan magnetik luar, maka partikel magnetite ini memiliki banyak aplikasi, salah satu dari aplikasi ini adalah untuk membawa obat ke tempat tujuan dalam tubuh manusia (drug delivery target) [2].

Pada penelitian ini dilakukan pembuatan kontur nilai suseptibilitas magnetik $\left(\chi_{m}\right)$ dan massa $\left(\chi_{\text {mass }}\right)$ pasir pantai Gandoriah Pariaman Sumatera Barat.

\section{METODE PENELITIAN}

\section{Pengambilan Sampel}

Sampel yang digunakan dalam penelitian ini berasal dari pinggir pantai Gandoriah. Jumlah titik lokasi sampel sebanyak 25 titiklokasi dengan jarak horizontal (samping pantai) masing-masing lokasi adalah 10 meter. Masing-masing titik lokasi sampel berjumlah $0,5 \mathrm{~kg}$ dan cara pengambilan sampel dilakukan dengan metode teknik sampling yaitu metode zigzag untuk satu lokasi dan juga untuk seluruh titik lokasi.

\section{Proses Pemisahan menggunakan Iron Sand Separator (ISS)}

Sampel yang sudah diambil dari lokasi kemudian dibawa ke Laboratorium Instrumen tasi dan Magnetik Jurusan Fisika Universitas Riau menggunakan wadah untuk dikeringkan.
Sampel yang telah melewati proses penger ngan kemudian ditimbang untuk mengetahui massa sampelnya $\left(M_{s}\right)$. Sampel yang telah melewati proses pengeringan dan penimba ngan kemudian dipisahkan mineral magnetik nya yang berupa konsentrat dari mineral non magnetik dengan menggunakan alat Iron Sand Separator. Pemisahan dilakukan hanya 1 kali proses, dimana sampel yang terdiri dari $0,5 \mathrm{~kg}$ konsentrat hasil pemisahan dengan Iron Sand Separator ini dinamakan dengan konsentrat I. Selanjutnya dengan menggunakan magnet batang $(\mathrm{NdFeB})$ maka konsentrat I dapat dipisahkan lebih jauh antara butiran magnetik dan pasir, hasil pemisahan ini dinamakan dengan konsentrat II.

\section{Pengukuran Tingkat Kemagnetan Sampel}

Setelah konsentrat partikel magnetik diperoleh dengan menggunakan magnet batang, maka dilakukan penimbangan terhadap konsentrat tersebut. Melalui perbandingan massa konsentrat dan massa sebelum pemisahan (massa sampel), maka perbandingan antara massa konsentrat dan massa sampel didapatkan nilai tingkat kemagnetan (magnetic degree).

\section{Pengukuran Induksi Magnetik}

Pertama dilakukan pengukuran Induksi magnetik solenoid tanpa inti dengan meng gunakan solenoid yang terdiri dari 2500 lilitan dengan diameter $3 \mathrm{~cm}$ dan panjang $10 \mathrm{~cm}$ dan juga menggunakan sensor Magnetic Probe Pasco PS- 2162. Terlebih dahulu ditentukan induksi magnetik solenoid $\mathrm{B}_{0}$ untuk jarak yang tetap yaitu $1 \mathrm{~mm}$ antara ujung tengah solenoid dengan Magnetic Probe Pasco PS- 2162. Arus yang diberikan bervariasi yaitu 0,1 A, 0,2 A, 0,4 A, 0,6 A dan 0,8 A. kemudian ditentukan induksi magnetik solenoid $\mathrm{B}_{0}$ untuk jarak yang bervariasi yaitu $1 \mathrm{~mm}$ sampai $5 \mathrm{~mm}$ dengan arus yang konstan yaitu $0,8 \mathrm{~mA}$. Selanjutnya sampel yang sudah ditimbang yang terdiri dari 25 sampel terlebih dahulu ditentukan nilai induksi magnetik totalnya dengan cara 
dimasukkan kedalam rongga solenoid yang telah dihubungkan dengan arus listrik, kemudian diukur induksi magnetik total $B_{T}$ menggunakan sensor Magnetic Probe Pasco PS-2162. Untuk masing-masing sampel pengukuran induksi magnetik total dari 25 sampel dilakukan dengan memberikan arus yang bervariasi yaitu 0,1 A, 0,2 A, 0,4 A, 0,6 A dan 0,8 A untuk jarak yang tetap (1 mm) dari ujung tengah solenoid. Pasir besi yang telah dipisahkan dengan mineral magnetiknya kemudian diukur besar induksi magnetik total untuk setiap konsentrat II dari 25 titik lokasi. Konsentrat II kemudian dimasukkan kedalam solenoid yang dihubungkan dengan arus listrik selanjutnya diukur nilai induksi magnetik total $B_{T}$ menggunakan sensor Magnetic Probe Pas co PS-2162. Pengukuran induksi magnetik total dari konsentrat dilakukan dengan mem berikan arus yang bervariasi yaitu $0,1 \mathrm{~A}, 0,2$ A, 0,4 A, 0,6 A dan 0,8 A untuk jarak yang tetap $(1 \mathrm{~mm})$ dari ujung tengah solenoid.

\section{X-Ray Fluorecence (XRF)}

XRF merupakan teknik analisis unsur yang terkandung dalam sampel dengan menggunakan prinsip spektrometri. Prinsip ini digunakan untuk mengukur komposisi unsurunsur suatu material, terutama yang terdapat dalam batuan atau mineral.Teknik ini cepat dan tidak merusak sampel. Analisis unsur dilakukan secara kualitatif dan kuantitatif. Analisa kualitatif dilakukan untuk menga nalisis jenis unsur yang terkandung dalam bahan dan analisa kuantitatif dilakukan untuk menentukan konsentrasi unsur dalam bahan [3]. Proses selanjutnya dilakukan uji XRF. Uji XRF dilakukan dalam 2 keadaan, yaitu sampel sebelum dipisahkan dari ISS dan setelah pemisahan menggunakan ISS.

\section{Pemetaan Nilai Suseptibilitas Magnetik}

Setelah didapatkan nilai suseptibilitas dari sampel dan konsentrat maka selanjutnya dilakukan pembuatan kontur suseptibilitas magnetik dengan menggunakan software "surfer" yang telah diinstal di komputer yang digunakan. Software "surfer" merupakan salah satu perangkat lunak yang digunakan untuk pembuatan peta kontur dan pemodelan tiga dimensi yang berdasarkan pada grid. Perangkat lunak ini melakukan plotting data tabular XYZ tak beraturan menjadi lembar titik-titik segiempat (grid) yang beraturan. Dimana grid merupakan serangkaian garis vertical dan horizontal yang dalam "surfer" berbentuk segiempat dan digunakan sebagai dasar pembentuk kontur dan surface tiga dimensi.

\section{HASIL DAN PEMBAHASAN}

\section{Pemetaan Nilai Suseptibilitas Magnetik Sampel}

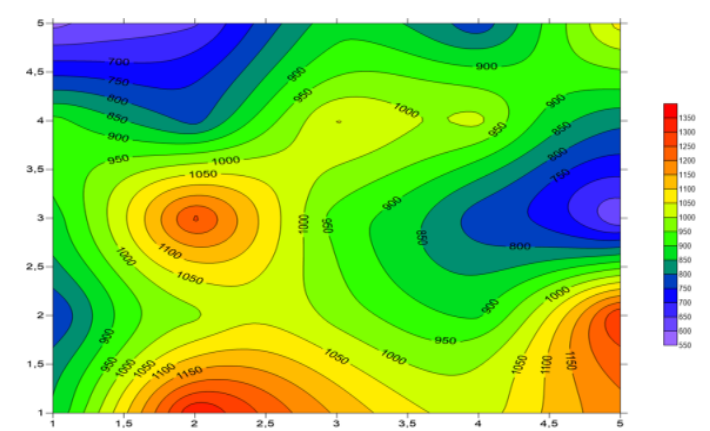

Gambar 1. Kontur suseptibilitas magnetik sampel 2-D.

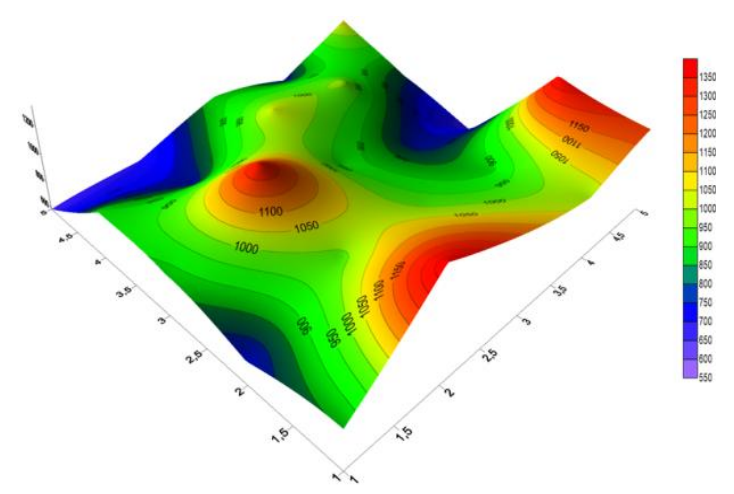

Gambar 2. Kontur suseptibilitas magnetic sampel 3-D.

Skema warna pada peta kontur menun jukkan rentang nilai dari suseptibilitas mag netik sampel. Warna ungu menunjukkan rentang nilai $(550-600) \times 10^{-5}$, warna biru menunjukkan rentang nilai $(700-750) \times 10^{-5}$, warna hijau menunjukkan rentang nilai (900- 
$950) \times 10^{-5}$, warna kuning menunjukkan rentang nilai (1050-1100) $\times 10^{-5}$, warna orange menun jukkan rentang nilai $(1150-1200) \times 10^{-5}$ dan warna merah menunjukkan rentang nilai $(1300-1350) \times 10^{-5}$.Nilai suseptibilitas magnetik sampel yang diperoleh berada dalam interval nilai suseptibilitas magnetik mineral ilmenite (antiferromagnetik; $\mathrm{FeTiO}_{3}$ ) yaitu $220 \times 10^{-5}$ $380000 \times 10^{-5}$. Berdasarkan kontur 2 dimensi dan 3 dimensi terlihat bahwa nilai suseptibi litas magnetik sampel yang dihasilkan me ngalami peningkatan kearah yang mende kati air laut. Peningkatan ini diduga disebab kan oleh pergerakan bolak balik pasir pantai oleh arus air laut ketika tejadi gerakan bolak balik air laut disekitar tepi pantai ini.

\section{Pemetaan Nilai Suseptibilitas Magnetik Konsentrat}

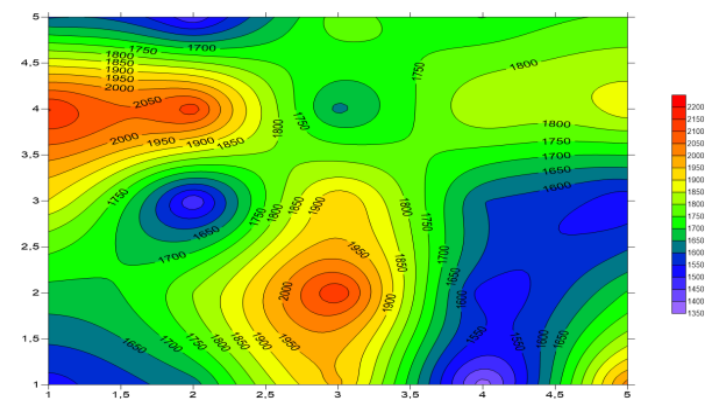

Gambar 3. Kontur suseptibilitas magnetik konsentrat 2-D.

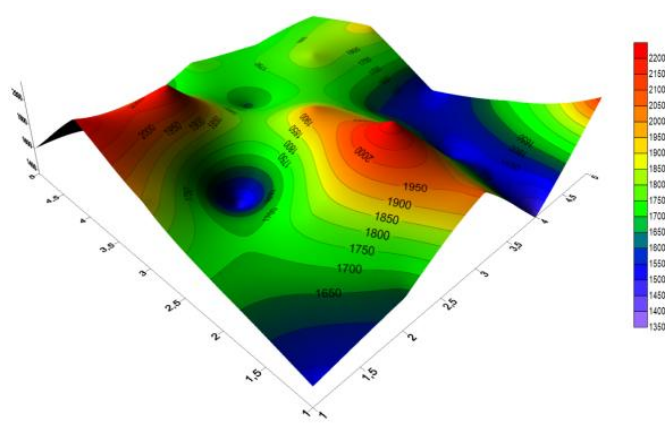

Gambar 4. Kontur suseptibilitas magnetic konsentrat 3-D.

Nilai suseptibilitas magnetik konsentrat pasir pantai ini ditampilkan dalam bentuk warna yaitu mulai dari ungu sampai merah. Warna ungu menunjukkan rentang nilai (1350$1400) \times 10^{-5}$, warna biru menunjukkan rentang nilai $(1500-1550) \times 10^{-5}$, warna hijau menun jukkan rentang nilai $(1700-1750) \times 10^{-5}$, warna kuning menunjukkan rentang nilai (1850$1900) \times 10^{-5}$, warna orange menunjukkan rentang nilai $(1950-2000) \times 10^{-5}$ dan warna merah menunjukkan nilai $(2150-2200) \times 10^{-5}$. Nilai suseptibilitas magnetik konsentrat berada dalam interval nilai suseptibilitas magnetik mineral ilmenite(antiferromagnetik; $\mathrm{FeTiO}_{3}$ ) yaitu $220 \times 10^{-5}-380000 \times 10^{-5}$. Nilai susep tibilitas magnetik konsentrat yang dihasilkan bervariasi dalam kisaran antara (1367,55$2155,90) \times 10^{-5}$.

\section{Pemetaan Nilai Suseptibilitas Massa Sampel}

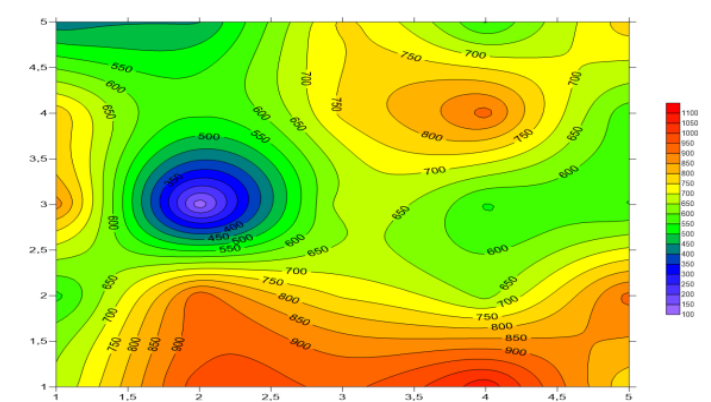

Gambar 5. Kontur suseptibilitas massa sampel 2-D.

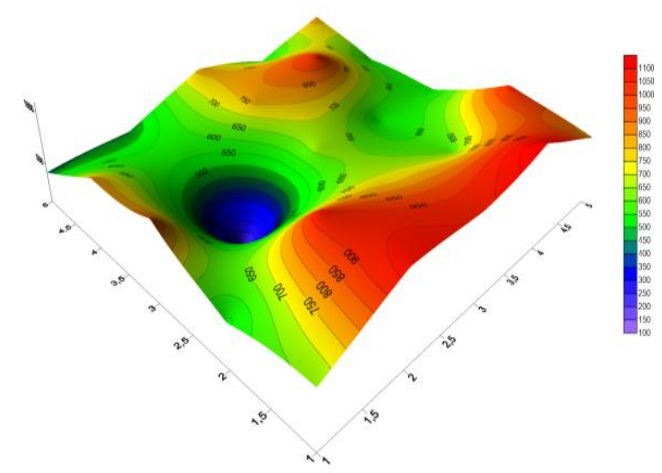

Gambar 6. Kontur suseptibilitas massa sampel 3-D.

Nilai suseptibilitas massa sampel yang di dapat dari hasil penelitian di Pantai Gandoriah Pariaman Sumatera Barat. Warna ungu men unjukkan rentang nilai $(100-150) \times 10^{-8} \mathrm{~m}^{3} / \mathrm{Kg}$, warna biru menunjukkan rentang nilai (300$350) \times 10^{-8} \mathrm{~m}^{3} / \mathrm{Kg}$, warna hijau menunjukkan rentang nilai $(550-600) \times 10^{-8} \mathrm{~m}^{3} / \mathrm{Kg}$, warna kuning menunjukkan rentang nilai (700$750) \times 10^{-8} \mathrm{~m}^{3} / \mathrm{Kg}$, warna orange menunjukkan rentang nilai $(800-850) \times 10^{-8} \mathrm{~m}^{3} / \mathrm{Kg}$ dan warna merah menunjukkan rentang nilai (1050$1100) \times 10^{-8} \mathrm{~m}^{3} / \mathrm{Kg}$. Nilai suseptibilitas massa 
sampel berada dalam interval nilai susep tibilitas massa ilmenite (antiferro mag netik; $\mathrm{FeTiO}_{3}$ ) yaitu $46 \times 10^{-8} \mathrm{~m}^{3} / \mathrm{kg}-80000 \times 10^{-8}$ $\mathrm{m}^{3} / \mathrm{Kg}$ [3]. Nilai suseptibilitas massa sampel mengalami peningkatan kearah yang mende kati air laut. Peningkatan ini sesuai dengan suseptibilitas magnetik dari sampel. Pening katan ini diduga terjadi karena pergerakan dari pasir pantai akibat aliran atau gerakan air laut disekitar tepi pantai.

\section{Pemetaan Nilai Suseptibilitas Massa Konsentrat}

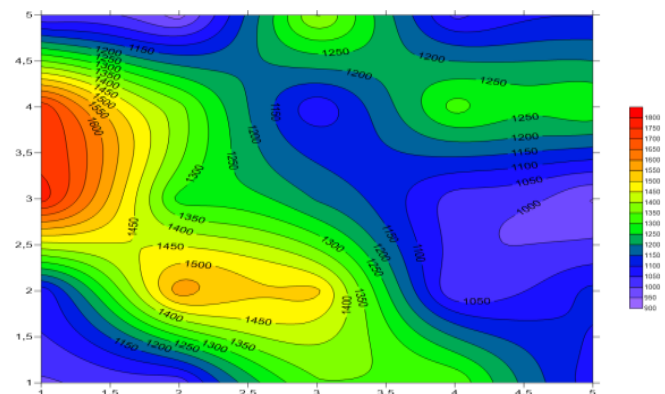

Gambar 7. Kontur suseptibilitas massa konsentrat 2-D.

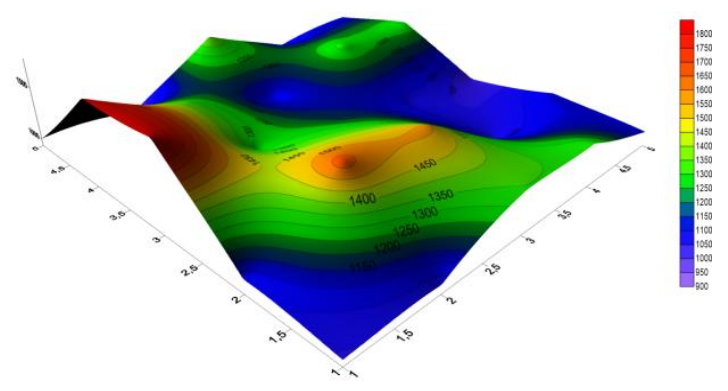

Gambar 8. Kontur suseptibilitas massa konsentrat 3-D.

Rentang nilai suseptibilitas massa konsen trat ini ditampilkan dalam berbagai bentuk warna, mulai dari warna unggu hingga merah. Warna ungu menunjukkan rentang nilai (900$950) \times 10^{-8} \mathrm{~m}^{3} / \mathrm{Kg}$, warna biru menunjuk kan rentang nilai $(1050-1100) \times 10^{-8} \mathrm{~m}^{3} / \mathrm{Kg}$, warna hijau menunjukkan rentang nilai (1300$1350) \times 10^{-8} \mathrm{~m}^{3} / \mathrm{Kg}$, warna kuning menunjuk kan rentang nilai $(1450-1500) \times 10^{-8} \mathrm{~m}^{3} / \mathrm{Kg}$, warna orange menunjukkan rentang nilai (1550-1600) $\times 10^{-8} \mathrm{~m}^{3} / \mathrm{Kg}$ dan warna merah menunjukkan rentang nilai $(1750-1800) \times 10^{-8}$ $\mathrm{m}^{3} / \mathrm{Kg}$. Nilai suseptibilitas massa konsentrat berada dalam interval nilai susep tibilitas massa ilmenite (antiferro mag netik; $\mathrm{FeTiO}_{3}$ ) yaitu $46 \times 10^{-8} \mathrm{~m}^{3} / \mathrm{Kg}-80000 \times 10^{-8} \mathrm{~m}^{3} / \mathrm{Kg}$. Variasi nilai suseptibilitas massa konsentrat berada dalam kisaran rentang nilai( 927,41 $1774,28) \times 10^{-8} \mathrm{~m}^{3} / \mathrm{Kg}$.

\section{Penentuan Komposisi Sampel dan Konsentrat}

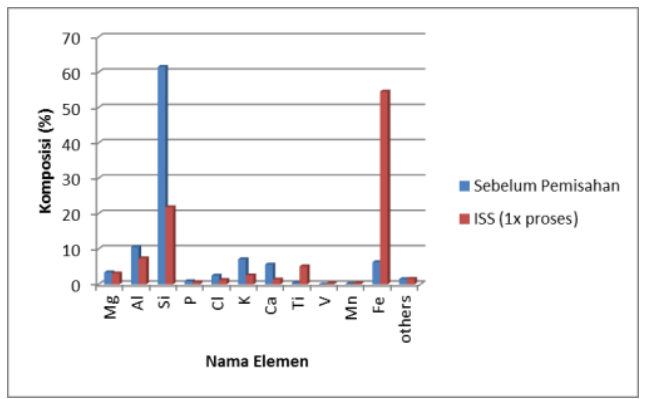

Gambar 9. Grafik perbandingan komposisi elemen pasir pantai sebelum dan sesudah pemisahan menggunakan ISS (1x proses).

Perbedaan komposisi sebelum dan se sudah pemisahan terlihat dengan adanya penambahan dan pengurangan yang terjadi pada elemenelemen tertentu.Pada elemen Fe komposisinya bertambah setelah dilakukan pemisahan yaitu dari 6,276 \% menjadi 54,549\%. Peningkatan persentase $\mathrm{Fe}$ dalam pasir besi menggunakan metode ball milling dan kopre sipitasi dilakukan oleh beberapa peneliti [4]. Penambahan komposisi lainnya juga terjadi pada elemen Ti, V dan Mn. Pada ele men Ti penambahan komposisinya lebih besar dibandingkan elemen $\mathrm{V}$ dan $\mathrm{Mn}$ karena elemen $\mathrm{Ti}$ telah bergabung dengan elemen $\mathrm{Fe}$ menjadi satu butiran dalam bentuk aglomerasi. Elemen Ti bertambah dari $0,441 \%$ menjadi $5,102 \%$.Ini mengkonfirmasi hasil perhitungan suseptibilitas magnetik bahwa nilai susep tibilitas magnetik ada dalam interval Ilmenite $\left(\mathrm{FeTiO}_{3}\right)$. Beberapa elemen lain seperti $\mathrm{Mg}$, $\mathrm{Al}, \mathrm{Si}, \mathrm{P}, \mathrm{Cl}, \mathrm{K}$ dan $\mathrm{Ca}$ mengalami penurunan setelah dilakukan pemisahan. Penurunan komposisi pada elemen ini mengandung unsur magnetik didalamnya tetapi sangat sedikit karena partikel-partikel lainnya sudah terpisah. 


\section{KESIMPULAN}

Berdasarkan hasil penelitian yang telah diperoleh dan analisa data yang telah dilakukan, maka dapat diambil beberapa kesimpulan sebagai berikut. Berdasarkan hasil mapping dari sampel maka nilai suseptibilitas magnetik sema kin besar mengarah ke laut. Pemetaan dari suseptibilitas magnetik sampel dan suseptibilitas magnetik konsentrat memiliki nilai berturut-turut sebesar $603,3 \times$ $10^{-5}-1351,46 \times 10^{-5}$ dan $1447,99 \times 10^{-5}-$ $2155,90 \times 10^{-5}$, hal ini menunjukkan bahwa nilai suseptibilitas mgnetik sampel dan suseptibilitas magnetik konsentrat berada dalam interval nilai suseptibilitas magnetik ilmenite (antiferromagnetik) yaitu $220 \times 10^{-5}-$ $380000 \times 10^{-5}$. Pemetaan dari suseptibilitas massa sam pel dan suseptibilitas massa konsentrat memiliki nilai berturut-turut sebesar $422,4 \times 10^{-8} \mathrm{~m}^{3} / \mathrm{Kg}-1086,85 \times 10^{-8} \mathrm{~m}^{3} / \mathrm{Kg}$ dan $927,41 \times 10^{-8} \mathrm{~m}^{3} / \mathrm{Kg}-1774,28 \times 10^{-8}$ $\mathrm{m}^{3} / \mathrm{Kg}$, hal ini menunjukan bahwa nilai suseptibilitas magnetik sampel dan suseptibilitas magnetik konsentrat berada dalam interval nilai suseptibilitas magnetik ilmenite ( anti ferromagnetik) yaitu $46 \times 10^{-8}$ $\mathrm{m}^{3} / \mathrm{Kg}-80000 \times 10^{-8} \mathrm{~m}^{3} / \mathrm{Kg}$. Dari analisa XRF di dapat bahwa komposisi dari $\mathrm{Fe}$ meningkat setelah di ISS $1 \times$ proses dari 6,276 $\%-54,549 \%$. Namun elemen Ti bertambah dari $0,441 \%-5,102 \%$.

\section{REFERENSI}

1. Sektor Pertambangan Sumbar Prov. (2014). Diakses pada 25 Maret 2018, URL: https://www.sumbarprov.go.id/deta ils/news/2700.

2. Nguyen, D. T. \& Kim, K. -S. (2014). Functionalization of magnetic nanoparticles for biomedical applications. Korean journal of Chemical Engineering, 31, 1289-1305.

3. Hunt, C. P., Moskowitz, B. M., \& Banerjee, S. K. (1995). Magnetic Properties of Rocks and Minerals. Rock Physics and Phase Relations: a Handbook of Physical Constants, 3, 189-204.

4. Kurniawan, C., Eko, A. S., Ayu, Y. S., Sihite, P. T. A., Ginting, M., Simamora, P., \& Sebayang, P. (2017). Synthesis and Characterization of Magnetic Elastomer based PEG-Coated $\mathrm{Fe}_{3} \mathrm{O}_{4}$ from Natural Iron Sand. IOP Converence Series: Materials Science and Engineering, 202 (1), 012051. 